\title{
Barriers and facilitators affecting vasectomy acceptability (a multi stages study in a sample from north eastern of Iran), 2005-2007
}

\author{
Afsaneh Keramat ${ }^{1 *},{\text { Afsaneh } \text { Zarei }^{2} \text { and Masoumeh Arabi }}^{2}$
}

\begin{abstract}
Background: In this study we aimed to find factors affecting vasectomy acceptability in Shahroud (north eastern Iran).

Methods: This study was carried out in three stages. The first stage was a survey of couples that had the vasectomy procedure during 2004-2007 in the Shahroud area. In the second stage of the study we compared characteristics of the cases (the couples who had the vasectomy procedure during the study period) and controls (including couples with at least one child that choose other contraceptive methods excluding a vasectomy) using $\chi^{2}$ and T student tests. In the third stage of the study we aimed to assess the knowledge and attitudes of those who did not choose to have a vasectomy as there contraception method by filling out questionnaires in personal interviews.
\end{abstract}

Results: An increasing trend toward the vasectomy procedure was observed during 2005 to 2007. We found positive associations between male and female educational levels and choosing to have a vasectomy $(p<0.05)$. Majority of women (88.44\%) thought that their husbands would prefer to have a tubectomy to a vasectomy.

Conclusion: The study results show a necessity for both couples to participate in educational programs about the vasectomy procedure.

Keywords: vasectomy family planning, permanent method

\section{Background}

The vasectomy procedure is a safe, simple and permanent method of contraception and has a failure rate of less than $1 \%$ [1]. It is less expensive and equally as effective as female sterilization; however, vasectomies are one of the least used and least known methods of contraception throughout the world [2]. Worldwide, an estimated 33 million married women between 15 to 49 years old (less than $3 \%$ ) rely on their partner's vasectomy for contraception [3].

Garcia Moren and co-workers suggested that greater spreading of information regarding the vasectomy procedure as a contraceptive method, greater links between male needs and the vasectomy procedure, and maintaining or increasing access to family planning [4].

\footnotetext{
* Correspondence: keramat1@yahoo.com

'Reproductive Health Department, Shahroud University of Medical Sciences, Shahroud, Iran

Full list of author information is available at the end of the article
}

In a nationwide practice-based survey in the United States conducted on 719 men receiving vasectomies, the researchers found that in spite of the variety of the U.S. population, vasectomy recipients are a homogeneous group [5].

Overall the prevalence of vasectomies is lower in developing countries. In Asia, with the exception of Bhutan, Iran, and the Republic of Korea, the occurrences of vasectomy has gradually declined over the past 15 years [6].

In the Islamic Republic of Iran, between 1993 and 2004, 500 training courses were conducted in public sector institutions. During the same period, an estimated 375,000 Iranians underwent the procedure, raising the prevalence of vasectomy from $0 \%$ to $3.5 \%$ in national contraception [7]. As it is mentioned in other reports, although the worldwide frequency of vasectomy is still much lower than 
tubectomy (3\%-6\% versus $28 \%$ ), men are going to accept more responsibility for family planning [8].

In this study we aimed to find barriers and facilitators affecting vasectomy acceptability in Shahroud area (north eastern Iran) during 2005-2007.

\section{Materials and methods}

This study that was approved by Research Committee of Shahroud Medical University, and was carried out in three stages. The first stage was a survey on couples that had a vasectomy during 2005-2007 in Shahroud area (in north east Iran). In this stage we assessed the number and characteristics of couples who chose this method and where they sourced their information about vasectomies from. Demographic characteristics that we assessed in this stage of study included age, education, occupation, age at marriage, number of child and the income of the couples. We have tried to find the association between the couples studied characteristics and their sources of information, and the number of couples that chose to have a vasectomy during the study period (2005-2007) using chi-square and t students' test statistical methods.

The second stage was a case-control study. The case group included couples who underwent the vasectomy procedure during the study period (all of the samples from first stage of study that lived in city area) and the study controls included couples with at least one child that received other contraceptive methods. The controls were selected randomly from a list of couples that underwent other contraceptive methods, except vasectomy, created from the centres' databases during the study period with same number of cases from each centre. Then we compared characteristics of case and controls using $\chi^{2}$ and $T$ student test.

In third stage of study we aimed to evaluate the knowledge and attitude of those who did not choose to have a vasectomy as their contraception method by interviewing women of the control group.

Data collected for this part of the study included filling in questionnaires through personal interviews. We informed the clients about the goals and the process of the study clearly in their own language (Persian). We have interviewed clients who agreed to participate; the consent was verbal in all of the health centres. The patients' identity was not revealed and patients' data was kept confidential.

\section{Results}

In the first stage of the study we have found a total of 311 couples who underwent the vasectomy procedure during 2005 to 2007 . The mean of the age of men and women were $39.5 \pm 7.7$ and $33.1 \pm 6.5$, respectively. As it is shown in table $1,19.4 \%$ of men had more than 12 years of school education and $36.6 \%$ of them were educated between 5-9 school years. Among women 9.6\% had more than 12 years of school education and $35.4 \%$ between 9 to 12 schooling years. Majority $(85.5 \%)$ of vasectomy recipients were from urban areas. The trend towards vasectomy during the study period is shown in table 1 . We have found a sharp increase in the numbers of couples who have chosen to have a vasectomy between 2005 and 2006. There were no significant associations between couples's demographic characteristics during the mentioned years. But we have found a significant difference in sources of information about vasectomy during 3 years (2005-2007) (table 1).

In the second stage of the study we compared characteristics of couples (gathered from the first stage) who accepted the vasectomy procedure (case group), with couples that chose other contraceptive methods (control group). There were significant relationships between male and female educational level and choosing to have a vasectomy $(\mathrm{p}<0.05)$.

The level of education was significantly higher in the vasectomy group as compared with those who had chosen tubectomy among both males and females $(\mathrm{p}<0.05)$ (table 2). Vasectomy receiving couples also had lower age and lower child numbers and higher income than couples who chose tubectomy. Even after adjustment for child number and age, comparison of vasectomy group with couples that had chosen non permanent methods revealed that the education level in the vasectomy group was significantly lower $(\mathrm{p}<0.05)$.

In third stage of the study we evaluated that the knowledge and attitude of those who did not choose vasectomy as a contraception method by interviewing women of the control group of stage 2 (table 3 ). There was no significant association between the knowledge and attitude about vasectomies as a kind of contraception. The higher and lower knowledge and attitude scores belong to the users of injectable methods (such as Depot medroxyprogesterone acetate) and condom, respectively. We also have found that there is no significant difference in knowledge and attitude about vasectomy between tubectomy and non permanent contraception receivers. Couples who have chosen tubectomy had significantly higher mean of age and child number compared with non permanent method users $(\mathrm{p}<0.05)$.

Assessment of the attitude towards vasectomy among women that were using contraceptive methods other vasectomy, displayed that majority of them did not agree with a permanent method (table 3). A majority (88.44\%) of the women who have chosen contraceptives other than vasectomy assume that their husbands would prefer tubectomy to vasectomy. Sixty two percent of these women did not know if their husbands are concerned 
Table 1 Frequency of couples that chose vasectomy and their demographic characteristics and sources of information during 2005-2007

\begin{tabular}{|c|c|c|c|c|c|}
\hline year & 2005 & 2006 & 2007 & total & significance \\
\hline Number of vasectomy's & 16 & 145 & 155 & 311 & \\
\hline Male age & & & & & $N S^{*}$ \\
\hline (mean) & $38.4 \pm 4.8$ & $39.2 \pm 7.3$ & $39.9 \pm 8.2$ & $39.5 \pm 7.7$ & \\
\hline Female age & & & & & $N S^{*}$ \\
\hline (mean) & $32 \pm 6.9$ & $33.2 \pm 6.9$ & $33.06 \pm 6$ & $33.1 \pm 6.5$ & \\
\hline \multicolumn{6}{|l|}{ Age of marriage } \\
\hline (mean) & $19 \pm 4.1$ & $21.8 \pm 4.6$ & $24.5 \pm 9.4$ & $22.9 \pm 7.5$ & $P<0.05$ \\
\hline Number of child & $2.7 \pm 1.1$ & $2.6 \pm 1.1$ & $2.8 \pm 1.2$ & & $N S^{*}$ \\
\hline Male education & & & & & $N S^{*}$ \\
\hline No education & $1(6.3)$ & $6(4.1)$ & $4(2.6)$ & $11(3.4)$ & \\
\hline Less than 5 yrs & $7(43.7)$ & $32(21.6)$ & $24(15.4)$ & $64(19.7)$ & \\
\hline $5-9$ & $4(25)$ & 49(33.1) & $64(41 /)$ & 117(36.6) & \\
\hline $9-12$ & $3(18 / 7)$ & $31(20 / 9)$ & $33(21.2)$ & $67(20.9)$ & \\
\hline more than 12 & $1(6 / 3)$ & $30(20 / 3)$ & $31(19.4)$ & $62(19.4)$ & \\
\hline \multicolumn{6}{|l|}{ Female education } \\
\hline No education & $0(0)$ & $3(2.1)$ & $3(1.9)$ & $6(1.9)$ & $N S^{*}$ \\
\hline Less than 5 yrs & $5(33.3)$ & 43(29.9) & $28(18.1)$ & $76(24.2)$ & \\
\hline $5-9$ & $5(33.3)$ & $32(22.2)$ & $54(34.8)$ & $91(29)$ & \\
\hline $9-12$ & $5(33.3)$ & $51(35.4)$ & $55(35.5)$ & $111(35.4)$ & \\
\hline more than 12 & $0(0)$ & $15(10.4)$ & $15(9.7)$ & 30(9.6) & \\
\hline \multicolumn{6}{|l|}{ Citizen } \\
\hline Urban & 14(87.5) & 127(84.7) & 130(86.7) & $271(85.5)$ & $N S^{*}$ \\
\hline Rural & $2(12.5)$ & 23(15.3) & 20(13.3) & $45(14.2)$ & \\
\hline \multicolumn{6}{|l|}{ Source of information } \\
\hline Media & $0(0)$ & $2(1.4)$ & $9(6.5)$ & 11(3.6) & $P<0.05$ \\
\hline Health workers & $14(87)$ & 117(79.1) & $74(53.6)$ & 205(67.9) & \\
\hline Friends and families & $2(12.5)$ & $27(18.2)$ & $51(37)$ & $80(26.5)$ & \\
\hline others & 0 & $2(1.4)$ & $4(2.9)$ & $6(2)$ & \\
\hline
\end{tabular}

* Non significant.

about impotency. Thirty five percent of interviewed women said that if they choose vasectomy they would prefer to keep it a secret.

\section{Discussion}

Worldwide, approximately 3-6\% of couples are using vasectomy as a method of contraception $[3,9]$. In the first stage of study we have found total 311 couples that underwent vasectomy during 2005 to 2007 . The population in Shahroud area is about 200,000, which means there are 62229 couples. It means that prevalence of vasectomy in Shahroud area is approximately 5\% that is similar to vasectomy's worldwide prevalence. Other studies also report the same occurrences in Iran. In this study we have found a sharp increase in numbers of couples who have chosen vasectomy between 2005 and 2006; however, there was no difference between 2006 and 2007 . By comparison, the vasectomy prevalence has progressively declined in Asia over the past 15 years with the exception of Bhutan, Iran and the Republic of Korea [6].
As It is displayed in table1, $19.4 \%$ of men had more than 12 years of school education and $36.6 \%$ of males that accepted vasectomy had between 5-9 of school education. Among women $9.6 \%$ were educated more than 12 years and $35.4 \%$ of females whom their husbands accepted vasectomy had between 9 to 12 years of school education. A majority (85.5\%) of vasectomy recipients were from urban area. Barone, M.A. and coworkers in their nationwide practice-based survey, have founded that Low-income, minority and less educated men were underrepresented among vasectomy recipients [5]. But in a survey of male subjects attending the Kingston Contraceptive Clinic for vasectomy, showed that usage of vasectomy was predominantly related to social class [10]. Some other studies report that those who choose vasectomy are belong to higher socioeconomic group [11]. A study in Nepal found that the major occupation of vasectomised men was agriculture $(73.7 \%)$, with a literacy rate of $83.0 \%$ [12]. We have found a significant difference in sources of information 
Table 2 frequency of study population (Second stage) divided by their contraception method, demographic characteristics and sources of information

\begin{tabular}{|c|c|c|c|c|c|}
\hline Case and control & Vasectomy group(cases) & non permanent contraception methods & Tubectomy & Total & Significant \\
\hline Number of vasectomy's & 269 & 168 & 43 & 480 & \\
\hline \multicolumn{6}{|l|}{ Male age } \\
\hline (mean) & $39.6 \pm 7.3$ & $38.8 \pm 7$ & $46.1 \pm 7.4$ & $39.9 \pm 7.5$ & $P<0.05$ \\
\hline \multicolumn{6}{|l|}{ Female age } \\
\hline (mean) & $33.03 \pm 6.3$ & $33.8 \pm 6.1$ & $45.2 \pm 5.9$ & $33.9 \pm 6.5$ & $P<0.05$ \\
\hline \multicolumn{6}{|l|}{ Age of marriage } \\
\hline (mean) & $23.18 \pm 6.6$ & $19.42 \pm 3.7$ & $18.55 \pm 3.7$ & $21.44 \pm 5.8$ & $P<0.05$ \\
\hline Number of child & $2.63 \pm 1.03$ & $2.3 \pm 0.65$ & $3.6 \pm 1.1$ & $2.6 \pm 0.98$ & $P<0.05$ \\
\hline male education & $n=272$ & $n=166$ & $n=42$ & $n=480$ & \\
\hline No education & $4(1.5)$ & $1(0.6)$ & $4(9.6)$ & $9(1.9)$ & $P<0.05$ \\
\hline Less than 5 yrs & $46(16.9)$ & 28(16.6) & $17(40.5)$ & $91(19)$ & \\
\hline $5-9$ & 100(36.8) & $35(21.1)$ & $9(21.4)$ & $144(30)$ & \\
\hline $9-12$ & $65(23.9)$ & $47(28.2)$ & $7(16.7)$ & 119(24.8) & \\
\hline more than 12 & $57(21)$ & 55(33.1) & $5(11.9)$ & $117(24.4)$ & \\
\hline Female education & $n=267$ & $n=168$ & $n=43$ & $n=478$ & \\
\hline No education & $3(1.1)$ & $2(1.2)$ & $3(7)$ & $8(1.7)$ & $P<0.05$ \\
\hline Less than 5 yrs & $54(20.2)$ & $38(22.6)$ & $22(51.2)$ & 114(23.8) & \\
\hline $5-9$ & $82(30.7)$ & 33(19.6) & $5(11.6)$ & $120(25.1)$ & \\
\hline $9-12$ & 101(37.8) & $62(36.9)$ & $10(23.3)$ & 173(36.1) & \\
\hline more than 12 & $27(10.1)$ & 33(19.6) & $3(7)$ & 63(13.2) & \\
\hline Source of information & $n=258$ & $n=142$ & $n=43$ & $n=444$ & \\
\hline Media & $11(4.3)$ & $1(0.7)$ & $1(2.3)$ & 14 & $P<0.05$ \\
\hline Health workers & $165(64)$ & $120(84.5)$ & 23(53.5) & 308 & \\
\hline Friends and families & $75(29.1)$ & $5(3.5)$ & $1(2.3)$ & 81 & \\
\hline other & $7(2.7)$ & 16(11.3) & 18(41.9) & 41 & \\
\hline
\end{tabular}

about vasectomy during 3 years (2005-2007) (table1). Although the most important sources of information about vasectomy in all 3 years were health providers, the role of health workers in acceptance of vasectomy was lower and the role of media and friends were higher in 2007 as compared with previous years.
Similarly in other studies, the most important sources of information about vasectomy were health providers followed by family or friends [5]. The result of present study shows the necessity of carrying out the educational programs for improving the knowledge and attitude of the health workers.

Table 3 frequency of study population (Third stage) in based on their attitude toward vasectomy

\begin{tabular}{|c|c|c|c|c|c|}
\hline Attitude & $\begin{array}{l}\text { Extremely } \\
\text { disagree }\end{array}$ & Disagree & No idea & Agree & $\begin{array}{l}\text { Extremely } \\
\text { agree }\end{array}$ \\
\hline & $N(\%)$ & $\mathrm{N}(\%)$ & $N(\%)$ & N (\%) & N (\%) \\
\hline I prefer tubectomy to vasectomy & $73(30.67)$ & $85(35.71)$ & $8(3.36)$ & 48(21.16) & 24(10.08) \\
\hline I do not agree with permanent Contraception & $41(17.29)$ & $48(20.25)$ & $6(2.53)$ & $82(34.59)$ & $60(25.31)$ \\
\hline Impotency is a side effect of vasectomy & 28(11.76) & $75(31.51)$ & $105(44.1)$ & $25(10.50)$ & $5(2.1)$ \\
\hline The side effects from having a vasectomy are greater than having a tubectomy & $75(31.51)$ & $120(50.42)$ & $21(8.82)$ & $15(6.3)$ & $7(2.94)$ \\
\hline If we decide to have a vasectomy I prefer not to tell anyone & $57(23.75)$ & $87(36.25)$ & $12(5)$ & $52(21.66)$ & $32(13.33)$ \\
\hline $\begin{array}{l}\text { I would choose to have a vasectomy only in if having a tubectomy was not } \\
\text { possible }\end{array}$ & $61(25.52)$ & 107(44.76) & $15(5.17)$ & $42(17.57)$ & $14(5.85)$ \\
\hline My family are opposed to vasectomy's & $65(10.12)$ & $112(47.25)$ & $7(2.95)$ & $39(16.45)$ & 14(5.9) \\
\hline I have suggested to male family members to consider having a vasectomy & 24(10) & $43(18)$ & 23(9.6) & $75(31.2)$ & $75(31.2)$ \\
\hline $\begin{array}{l}\text { My husband thinks that one of the side effects of having a vasectomy is } \\
\text { impotency }\end{array}$ & $9(3.8)$ & $42(15.57)$ & $150(62.76)$ & $31(12.97)$ & $7(2.92)$ \\
\hline My husband would prefer to have a tubectomy then a vasectomy & $3(1.26)$ & 23(9.66) & $11(4.62)$ & $116(48.73)$ & $85(35.71)$ \\
\hline My husband's family disagrees with tubectomy & 24(10) & $43(17.91)$ & 23(9.58) & $75(31.25)$ & $75(31.25)$ \\
\hline
\end{tabular}


Level of education was significantly higher in vasectomy group among both male and female (table2). Education level in vasectomy group was significantly lower than people that have chosen non permanent methods $(\mathrm{p}<0.05)$.

In our study, couples who have accepted vasectomy were significantly more educated than couples that have accepted tubectomy. They also had lower age, lower child number and higher income. Therefore we suggest specific consultations and education programs for people who have indications for choosing permanent methods of contraception.

Vasectomy is more common than female sterilization in only 5 countries. These countries are Bhutan, Denmark, the Netherlands, New Zealand and Great Britain. In 8 countries: Australia, Bhutan, Canada, the Netherlands, New Zealand, the Republic of Korea, Great Britain and the United States, the prevalence of vasectomy use exceed $10 \%$. New Zealand has the highest occurrence of vasectomy at 19.3 [13]. Although one of the most important reasons mentioned by couples who choose to have a vasectomy is the lower cost; $[14,15]$ however, in our study the higher socioeconomic level of people who accepted vasectomy as compared with tubectomy group shows that the mentioned factor does not have an important role in our area. Other causative factors to selection of vasectomy are lower side effects, mortality and simplicity of the surgical procedure of vasectomy [16,17]

In a cross-sectional study carried out in Iran, one of the most important reasons for vasectomy refusal was concern about complications, including the risk of sexual disability after vasectomy [18].

A descriptive study that was conducted in south-western Ethiopia displayed that men's choice of vasectomy as a method of contraception was $79 \%$. The prevalence of men that were not in agreement with vasectomy because of possible loss of children due to death or divorce was 21\%" [19].

In the third stage of present study after assessment the attitude about vasectomy only $12.6 \%$ of women were worried about impotency and the majority of the women who have chosen contraceptives, except vasectomy, thought that their husbands would prefer tubectomy to vasectomy. Therefore we suggest a consultation and specific educational programs for both males and females. Similar findings were reported in several previous studies [20-22].

Culture and community aspects influence the ability and willingness of men to obtain a vasectomy. In our study 35 percent of interviewed women said that they would prefer concealment about their contraception method if they choose vasectomy.

\section{Conclusion}

There was an increasing trend towards acceptance of vasectomy during the study period. The results of the study show an acceptable level of knowledge about vasectomy among users of other contraceptive methods. Iran's policy in requiring both men and women to take a class on modern contraception before receiving a marriage license and increasing knowledge about vasectomy might be important facilitators that can influence vasectomy acceptance. In our study couples that accepted the vasectomy procedure were significantly more educated than couples that accepted tubectomy, but they were significantly lower in education level compared with users of non permanent methods. For women, one of the most important barriers to acceptance of vasectomy is the negative attitude of men towards vasectomy.

Various strategies should be implemented that aim to increase vasectomy use:

1. Specific consultations for couples who accepted a permanent method especially tubectomy.

2 . The necessity of both couples participation in consultation sessions targeting men.

3. Vasectomy use can also be increased through targeting the staff and clinics at healthcare centres. Additional training should be offered for staff in order to create competent, committed staff who can effectively communicate with men. The staff members should encourage vasectomy.

\section{Acknowledgements}

We would like to thank all staff of Shahroud health centre and the Medical University of Shahroud for their cooperation and support during the data collection.

\section{Author details}

'Reproductive Health Department, Shahroud University of Medical Sciences, Shahroud, Iran. ${ }^{2}$ Student research committee, Shahroud University of Medical Sciences, Shahroud, Iran.

\section{Authors' contributions}

AK contributed to the study, design, analysis and acquisition of data to complete the final report. AZ and MA contributed study design and data collection, all authors approved the manuscript.

\section{Competing interests}

The authors declare that they have no competing interests.

Received: 3 August 2010 Accepted: 8 May 2011 Published: 8 May 2011

\section{References}

1. Dhar NB, Jones JS: Vasectomy: A simple snip? Indian J Urol 2007, 23(1):6-8.

2. Roy J, Pile JM: "Vasectomy: The Unfinished Agenda." ACQUIRE Project Working Paper. 2007, Web. 21 Nov. 2009.

3. Pile JM, Barone MA: Demographics of vasectomy-USA and international. Urol Clin North Am 2009, 36(3):295-305.

4. Garcia Moreno J, Solano Sainos LM: Acceptance and rejection of vasectomy in rural males. Rev Med Inst Mex Seguro Soc 2005, 43(3):205-14. 
5. Barone MA, Johnson CH, Luick MA, Teutonico DL, Magnani RJ: Characteristics of men receiving vasectomy in the United States, 19981999. Perspect Sex Reprod Health 2004, 36(1):27-33.

6. Corey L: Vasectomy use worldwide as of 2009 review. Rollins School of Public Health at Emory 2009.

7. Country report on the population and family planning program in the Islamic Republic of Iran. Tehran: Ministry of Health and Medical Education; 2003.

8. Comparing Muslim Countries' Policies on Contraception and Abortion: Global Public Health through a Feminist Lens. 2010 [http://www.earthpolicy.org/Updates/Update4ss.htm], [Internet] [cited 2010 Dec 30].

9. Family Planning Worldwide: 2008 Data Sheet. Population Reference Bureau. 2008 [http://www.prb.org/pdf08/fpds08.pdf], [Internet] [cited 2010 Dec 30].

10. Parsons MA, Wood HA: Demographic and socio-economic characteristics of men choosing vasectomy. J Biosoc Sci 1978, 10:133-9.

11. Eisenberg ML, Henderson JT, Amory JK, Smith JF, Walsh TJ: Racial differences in vasectomy utilization in the United States: data from the national survey of family growth. Urology 2009, 74:1020-4.

12. Subba N: Demographic assessment on vasectomy clients of Sankhuwasabha Nepal. Nepal Med Coll J 2003, 5:98-9.

13. Barone Mark, John Pile: "Demographics of Vasectomy-USA and International.". EngenderHealth 2009, Web. 21 Nov. 2009.

14. Finger WR: Attracting Men to Vasectomy". Network 18(3) [http://www.fhi. org/en/rh/pubs/network/v18_3/nw182ch8.htm], Retrieved 2006-05-15.

15. Smith GL, Taylor GP, Smith KF: Comparative risks and costs of male and female sterilization. American Journal of Public Health 75(4):370-374

16. Schwingl JPamela, Guess AHarry: Safety and effectiveness of vasectomy. Fertility and Sterility 2000, 73(5):923-936.

17. Awsare NS, Krishnan J, Boustead GB, Hanbury DC, McNicholas TA: Complications of vasectomy. Ann R Coll Surg Engl 2005, 87:406-10.

18. Kamyabi Z: A survey of the reasons for vasectomy refusal in couples who have chosen tubectomy as their contraceptive method. Saudi Med $J$ 2002, 23:752-4.

19. Dibaba A: Rural men and their attitude towards vasectomy as means of contraception in Ethiopia. Trop Doct 2001, 31:100-2.

20. Bunce A, Guest $G$, Searing $H$, Frajzyngier V, Riwa P, Kanama J, et al: Factors affecting vasectomy acceptability in Tanzania. Int Fam Plan Perspect 2007, 13-21.

21. Arevalo JA, Wollitzer AO, Arana S: Vasectomy: views of Latinos and white men. J Fam Pract 1987, 24:493-6.

22. Marchi NM, de Alvarenga AT, Osis MJ, Bahamondes L: Contraceptive methods with male participation: a perspective of Brazilian couples. Int Nurs Rev 2008, 55(1):103-9.

doi:10.1186/1447-056X-10-5

Cite this article as: Keramat et al:: Barriers and facilitators affecting vasectomy acceptability (a multi stages study in a sample from north eastern of Iran), 2005-2007. Asia Pacific Family Medicine 2011 10:5.

\section{Submit your next manuscript to BioMed Central and take full advantage of:}

- Convenient online submission

- Thorough peer review

- No space constraints or color figure charges

- Immediate publication on acceptance

- Inclusion in PubMed, CAS, Scopus and Google Scholar

- Research which is freely available for redistribution

Submit your manuscript at www.biomedcentral.com/submit
Biomed Central 